УДК 69

\title{
ИНФОРМАЦИОННАЯ МОДЕЛЬ ОБЪЕКТА СТРОИТЕЛЬСТВА НА ЭТАПАХ ПРОЕКТИРОВАНИЯ, СТРОИТЕЛЬСТВА И ЭКСПЛУАТАЦИИ
}

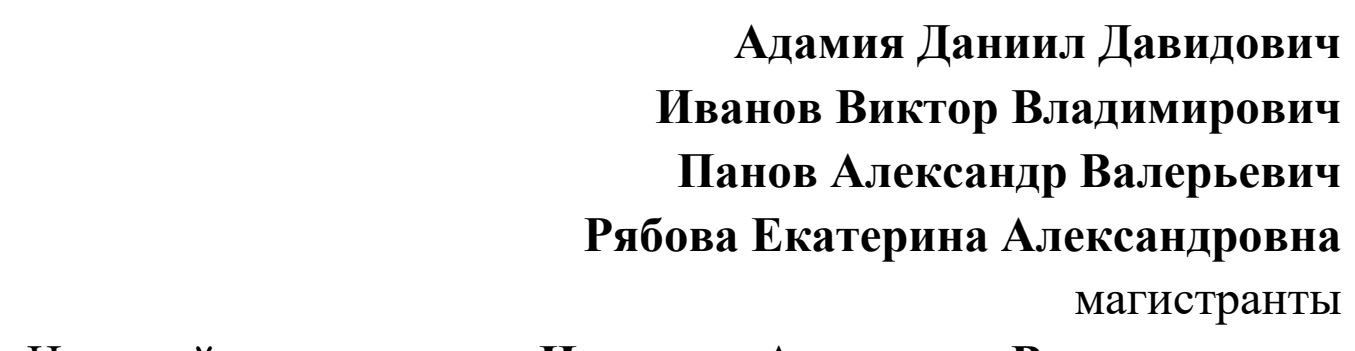

Научный руководитель: Игнатьев Александр Владимирович

д.т.н., доцент

Институт архитектуры и строительства

ФГБОУ ВО «Волгоградский государственный технический университет»

Аннотация: Рассматривается понятие информационной модели объекта капитального строительства и её разновидности. Описаны виды, состав, содержание, задачи и особенности применения цифровой информационной модели объекта капитального строительства на этапах его проектирования, строительства и эксплуатации.

Ключевые слова: информационное моделирование зданий, жизненный цикл объекта капитального строительства, информационная модель здания.

\section{INFORMATION MODEL OF THE CONSTRUCTION OBJECT AT THE STAGES OF DESIGN, CONSTRUCTION AND OPERATION}

\author{
Adamiya Daniil Davidovich \\ Ivanov Viktor Vladimirovich \\ Panov Alexander Valerevich \\ Ryabova Ekaterina Aleksandrovna \\ Scientific adviser: Ignatyev Alexander Vladimirovich
}

\begin{abstract}
The concept of the information model of the capital construction object and its varieties is considered. The article describes the types, composition, content, tasks and features of the application of the digital information model of the capital construction object at the stages of its design, construction and operation.

Key words: building information modeling, life cycle of a capital construction project, building information model.
\end{abstract}


В градостроительном кодексе Российской Федерации [1] информационная модель определена наряду с объектами капитального строительства и имеет следующее определение: "информационная модель объекта капитального строительства (далее - информационная модель) совокупность взаимосвязанных сведений, документов и материалов об объекте капитального строительства, формируемых в электронном виде на этапах выполнения инженерных изысканий, осуществления архитектурностроительного проектирования, строительства, реконструкции, капитального ремонта, эксплуатации и (или) сноса объекта капитального строительства".

Таким образом, процесс информационного моделирования зданий, также называемый BIM (Building Information Modeling), охватывает все этапы жизненного цикла объекта строительства, начиная с планирования и технического задания и заканчивая эксплуатацией, ремонтом и даже демонтажем [2, 3, 4] (рис. 1). И на всех этапах жизненного цикла объекта строительства участники строительного процесса работают в едином информационном пространстве с библиотеками элементов объектов промышленного и гражданского строительства и видов работ, составляющими основу Единого Классификатора. Информационная модель динамична, изменения в нее могут вноситься на любой стадии всеми участниками процесса.

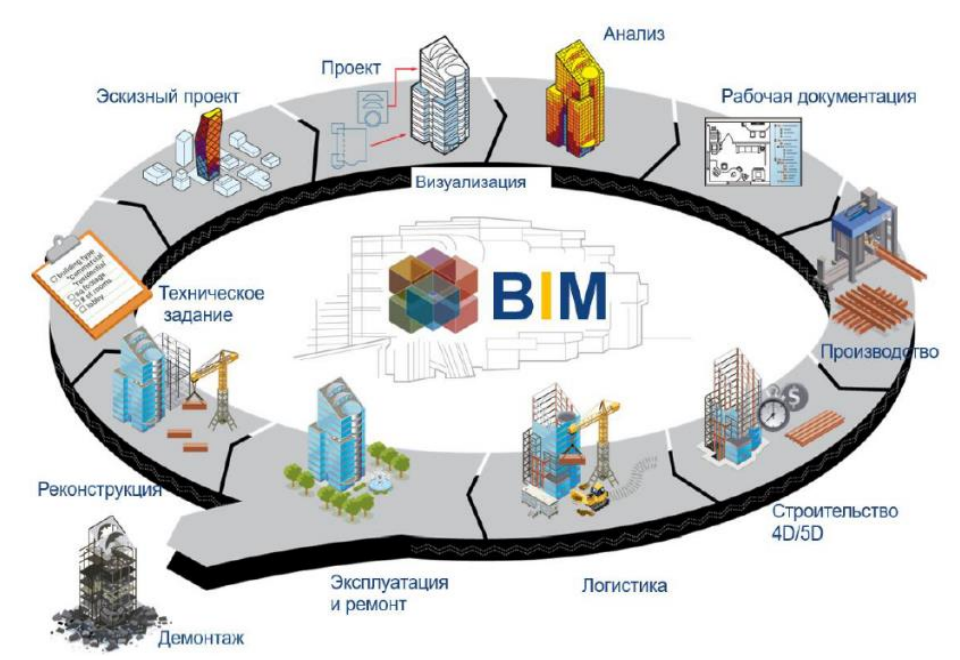

\section{Рис. 1. Структура информационной модели здания}

Информационное моделирование как подход к проектированию зданий предполагает, прежде всего, сбор, хранение и комплексную обработку в процессе проектирования всей архитектурно-конструкторской, технологической, экономической и иной информации о здании со всеми ее 
взаимосвязями и зависимостями, когда здание и все, что имеет к нему отношение, рассматриваются как единый объект.

Самая простая разновидность моделирования-3D. Она позволяет увидеть, как будет выглядеть планируемое здание (сооружение) еще до начала строительства. При добавлении изменений во времени к объекту 3D, мы получаем визуальную модель в формате 4D, что позволяет нам увидеть объект в любой момент времени и повысить точность планирования.

Более сложная модель 5D. Она включает стоимостные показатели по материалам, конструкциям и работам.

Информационно моделирование в процессе разработки проекта дает пользователю больше информации чем можно увидеть в реальном здании (сооружении), так как предоставляет данные о внутренних деталях объекта (скрытых работах). Программа хранит в себе информацию о материалах, которые использовались при строительстве. Это решает огромное количество проблем при дальнейшей эксплуатации здания. Также большим преимуществом ВIM технологий является то, что можно визуально оказаться в спроектированном здании и разобраться во всех деталях будущей постройки. Это помогает минимизировать количество ошибок в процессе проектирования здания.

На этапе строительства ВІМ-модель позволяет визуализировать процесс строительно-монтажных работ, оптимизировать календарно-сетевой график, избежать пространственно-временных коллизий, контролировать объемы работ на основе модели, осуществлять строительный контроль.

Основной задачей модели на этом этапе является эффективный контроль календарного графика строительства. На основе регулярной фиксации и занесения в модель выполненных объемов строительномонтажных работ за конкретный период.

В итоге мы имеем возможность объединить начальную 3D модель проекта с плановой и фактической, получив, таким образом, комплексную модель, в которой по каждому проектному элементу содержится следующая дополнительная информация:

- информация об используемых материалах элементов модели и физические показатели;

- срок выполнения работ по устройству проектных элементов модели;

- информация о фактически выполненных объемах работ. 
Сформировав комплексную модель проекта на определенную дату, появляется возможность поэтапно систематизировать полученные данные и провести их анализ.

Стоит отметить то, что сама информационная модель не используется непосредственно на строительной площадке. Строители работают по чертежам. Тем не менее, инженеры строительной площадки имеют постоянный доступ к актуальной модели. Модель при строительстве используется в случаях недостаточной информации на чертеже, разъяснений, решения спорных ситуаций.

Этап эксплуатации является самым продолжительным в жизненном цикле объекта и может составлять 50 и более лет. ВІМ-модель здесь используется для генерирования и управления информацией об объекте в течение всего его жизненного цикла, создается цифровой двойник.

Во время жизненного цикла объекта информационная модель обеспечивает:

- планирование технического обслуживания и ремонта;

- мониторинг эксплуатационных характеристик;

- планирование затрат на капитальные ремонты здания, обоснование финансовых расходов;

- прогнозирование годового бюджета на эксплуатацию объекта;

- создание концепции развития объекта, плана управления эксплуатацией;

- сопровождение договоров на коммунальные услуги.

Комплексный подход управления процессами эксплуатации предназначен для любого типа недвижимости: коммерческой, жилой, промышленной. Решение включает в свой состав модули для разнообразных задач. Но для эффективного функционирования модели на этапе эксплуатации необходимо своевременное ее обновление в зависимости от текущего состояния исходного объекта - модель должна жить и изменяться в соответствии со своей реальной копией.

\section{Список литературы}

1. Закон Российской Федерации "Градостроительный кодекс Российской Федерации" от 22 декабря 2004 № 190-Ф3 // Российская газета. с изм. и допол. в ред. от 30 декабря 2020

2. Талапов В.В. Технология ВIM: суть и особенности внедрения информационного моделирования зданий. М.: ДМК Пресс, 2015. 410 с. 


\section{3. Постановление Правительства Российской Федерации "Об} утверждении Правил формирования и ведения информационной модели объекта капитального строительства, состава сведений, документов и материалов, включаемых в информационную модель объекта капитального строительства и представляемых в форме электронных документов, и требований к форматам указанных электронных документов, а также о внесении изменения в пункт 6 Положения о выполнении инженерных изысканий для подготовки проектной документации, строительства, реконструкции объектов капитального строительства" от 15 сентября 2020 г. № 1431 // Собрание актов Президента и Правительства Российской Федерации.

4. СП 333.1325800.2017 «Информационное моделирование в строительстве. Правила формирования информационной модели объектов на различных стадиях жизненного цикла» // Минстрой России URL: https://minstroyrf.gov.ru/docs/16405/ (дата обращения: 12.04.2021).

(C) Д.Д. Адамия, В.В. Иванов, А.В. Панов, Е.А. Рябова, 2021 